\title{
17. Adapting university education in a digital and globally networked world
}

\section{Mona Jimenez}

Since 2003, the Moving Image

Archiving and Preservation Program (MIAP) at New York University has graduated nearly 90 new moving image preservation professionals. Practices for moving image archiving and preservation have changed dramatically since the programme began. In addition, 'born-digital' productions have become the norm. Thus, MIAP has needed to continually adapt to the increasingly broad nature of heritage collections, and to new approaches and practices aimed at maintaining perpetual access to moving image works. In addition, MIAP has encouraged these professionals to understand their work in a global context and to approach international collaborations in a spirit of exchange. Changes in MIAP have been informed by a set of principles present from the beginning of the programme, by an early and continued emphasis on a full spectrum of media types and by projects and initiatives undertaken by faculty, staff, students and alumni.
The Moving Image Archiving and Preservation Program (MIAP) at New York University was initiated in 2002 under the leadership of Professor Antonia Lant in the Department of Cinema Studies, a part of the Tisch School of the Arts. Cinema and television scholars were acutely aware of the need for perpetual access to moving images that serve as primary research materials and critical teaching resources for their disciplines. These scholars also were responding to national studies commissioned by the Library of Congress that had called for the creation of educational programmes to address audiovisual collections (Melville and Simmons, 1993; Murphy, 1997). The reports noted that archival, library and conservation training programmes did not cover the care and management of these collections, which were severely endangered due to obsolescence, deterioration and neglect.

In 2002, the department hired MIAP's first administrative coordinator, Alicia Kubes, followed by Professor Howard Besser as director. I joined the team in 2003, and in September 2003, the first class of graduate students began their two-year programme. As of May 2016, MIAP had graduated nearly 90 new moving image professionals who work in libraries, archives, museums, historical societies, corporate archives, television and radio, film/media distribution, audiovisual consulting firms and with the personal archives of creators and collectors. In addition to their contributions within their own organizations and regions, many have become leaders in audiovisual and digital preservation internationally.

MIAP emphasizes the study of history and theory coupled with hands-on practice accomplished through class projects and internships. Three internships are required of each student. Students have made a significant impact on a wide range of audiovisual collections through more than 200 internships and numerous post-graduate fellowships. In addition to the United States of America, students have been placed in internships in Argentina, Brazil, Czechia, Ghana, Greece, Israel, the Republic of Korea, the Philippines and Rwanda. 
International students have come to MIAP from Argentina, Canada, Chile, China, Colombia, Italy, the Republic of Korea, the Philippines, Thailand and Uruguay. MIAP faculty and staff have been committed to collaborations globally through leadership in educational efforts such as ICCROM's SOIMA, through working partnerships as part of the Audiovisual Preservation Exchange (APEX) and through preservation projects undertaken and promoted as part of the Orphan Film Symposium, among others. ${ }^{1}$ These efforts have been essential to infusing new content in MIAP and Cinema Studies courses that better reflects the conditions, practices and resources of archives, to exposing students to a broader range of preserved works and to encouraging meaningful collegial relationships across borders.

On the digital side, MIAP's adaptations have been many and continuous. When the programme started in 2003, the approaches to audiovisual archiving and preservation were substantially different, and few tools and resources were available to support digitization and digital preservation. Film scanning was in a prototype phase, and common wisdom still called for tape-to-tape preservation for videotape. Digitization cards were expensive and considered inferior and largely unreliable. At the time, there was much forecasting, with both excitement and worry, about the turn to tapeless digital production and the inevitability of file-based workflows for preservation. Impassioned debates were beginning in earnest about the choices of preservation target formats for magnetic media and film.

MIAP faculty and students engaged in these debates in the classroom and through research projects, and the curriculum started to shift to make space for the new skills and knowledge that we were all acquiring. MIAP has been nothing if not flexible; curriculum revisions have been many. Not a year goes by without heartfelt discussions among MIAP faculty and staff about how to be inclusive yet realistic about the addition of new content (and what can be sacrificed) given the fluid nature of the field. The spectrum of collections from seminal nineteenth-century films to ubiquitous twenty-first-century digital forms such as cellphone video and websites has meant that whole new skill areas have had to be added to our curriculum. ${ }^{2}$ Recently we added a brand new class to the first semester - Digital Literacy for Moving Image Archiving and Preservation alongside long-standing core classes such as Introduction to

1 APEX promotes international exchange on preservation practices through shared work on collections; see https://apexnyu. wordpress.com/. The Orphan Film Symposium is an international forum for archivists, scholars, curators, preservationists, technical experts, artists and media-makers devoted to making neglected film and media accessible; see www. nyu.edu/orphanfilm/.

2 The MIAP curriculum can be found at www.nyu.edu/tisch/ preservation/curriculum.html.
Moving Image Archiving and Preservation, or Moving Images and Sound: Basic Issues and Training. We felt that a basic introduction to the structure of digital files and how they are created, stored and accessed was foundational to most, if not all, the coursework to come.

In preparation for the SOIMA 2015 conference in Brussels, Aparna Tandon challenged me to articulate how MIAP has adapted to our field's increasing reliance upon digital tools and methods and our role as a member of the global field of moving image preservation. The following is my very personal take on what has driven our changes (albeit more concretely on the digital issues). I have attempted to articulate the 'why' (what core values or focal points in MIAP have enabled the changes) and the 'how' (how have we taken advantage of these conditions and adapted).

\section{Born-digital materials and methods}

MIAP was never a programme stressing analogue formats that 'woke up' to digital; rather there was significant attention to digital issues from the very first year. Professor Howard Besser, a Library of Congress Digital Pioneer and MIAP's director from 2003 to 2014, had a vision for MIAP that encompassed all forms of moving images and that anticipated both the need for management of files created through digitization and those 'born' as digital objects. He made it clear to our colleagues in Cinema Studies that we needed not only to address the care of older, more traditional, film and television materials but also to be attentive to new production processes and evolving practices predicated by new digital and networked environments. In addition, Besser and I both had a background in the creation and conservation of experimental media and media art, and we had worked extensively with still and moving images existing as files. Thus from the outset MIAP was promoted as a programme committed to the study of film, video and digital media. For example, Besser made sure that the very first outlines for the two-year curriculum included the course Digital Preservation as well as Handling Complex Media, which would address complex works like interactive multimedia, games and websites.

\section{A solid grounding in real world collections}

As noted above, MIAP has always balanced theories of preservation and access with hands-on work in real world collections through project-based learning and internships. In addition, we have always attended both to collections held in 'official' archives and to those that are held by creators and collectors, as well as accidental archives. Every collection and/or collector poses intriguing questions that force students to contrast best practices and ideal scenarios with less-than-ideal settings and a variety of 
needs, conditions and belief systems. There are fewer situations more instructive, for example, than trying to apply concepts of Open Archival Information Systems (OAIS) to emerging repositories where resources are scarce or non-existent, or beginning an inventory process for media where there is no metadata system in place. Because students take three internships, their experience with a resource-challenged organization can be balanced with an internship in a major institution where a student is exposed to highly developed metadata schemes or preservation processes.

Having students working in a variety of internships and projects with a range of institutions also means that MIAP must stay current; the education of our students must match the new tools and methods being adopted by memory organizations. For example, understanding that web archiving is becoming a standard part of acquisitions for many archives, we added sessions on web archiving to Digital Preservation, giving students hands-on practice with the tool Archive-It. We realized that students are increasingly confronted with born-digital materials while doing collection surveys in the class Collection Management, which was one of the precipitating factors for adding Digital Literacy. We have revamped Metadata for Moving Images numerous times, doubling the contact hours to ensure students have exposure to multi-institutional tools such as PREMIS or Archive Space, while at the same time preparing them to intelligently create simple metadata templates for smaller, community-based organizations.

\section{Care and preservation of videotape}

MIAP is unique in the amount of time and depth of practice that is devoted to video and television materials. In my opinion, the fact that we have been committed to video has strengthened the programme's ability to grow in the digital realm. The care and management of videotapes and video files is threaded throughout the curriculum, but the bulk of the training is provided in Video Preservation I and Video Preservation II. In these dedicated classes, students carry out digitization using in-house systems and also manage preservation projects with outside vendors. The students practice a full cycle of care, starting by opening a box of videotapes for evaluation and ending with a set of preservation master files and access copies stored on a network-attached storage (NAS) device. The cycle includes inspection, description (metadata), analysis of analogue characteristics, creation of a preservation plan, any needed treatments (cleaning, repair), digitization, documentation actions (more metadata), quality control, creation of viewing copies, creation of checksums, 'bagging' of all files into one package, uploading to storage, an additional integrity check and creation of a report.
Thus, by creating substantial space for video in the curriculum, the students get needed practice with a range of digital software and processes: automated tools for video capture, tools for the acquisition of file technical metadata and transcoding software, to name a few. They gain a direct understanding of issues such as file structures, storage planning, file integrity and the troubleshooting of digital errors. Each year, instructors add the latest tools for digitization, transcoding and quality assurance. While digital skills and methods are introduced in Digital Preservation and increasingly incorporated into the Film Preservation course, the video curriculum has been the primary way for students to gain solid skills with the software and systems that are also used with other media.

\section{Care and preservation of complex media works}

The inclusion of complex media works - those going beyond single channels or screens, works containing multiple digital file types and/or presented as installations or in networks jump-started our involvement with digital issues. To analyse multimedia for preservation and access, we needed to teach about file structure and sustainability even before digitization or digital repositories had become the norm. Using methods that may now be called 'media archaeology', students dissected and analysed complex works that contained audio, video, still images and text, all in digital form. Thus, from the beginning of the programme students learned practical skills with identification and risk assessment for file-based works and were exposed to various software for creation, display, description and storage.

This aspect of the curriculum involved us immediately in teaching about - and trying to give hands-on practice with preservation strategies just gaining attention, such as refreshing, migration and emulation. Feeling strongly that the students needed to experience older complex media works in their native environment, I created an Old Media Lab with legacy hardware and software. The lab has grown to include not only stations for analysing obsolete multimedia but also for teaching disk imaging and forensics software.

\section{Creative research at micro and macro levels}

In MIAP, research on digital issues has been undertaken both with external partners and individually by faculty, staff or students. Though in MIAP's beginning years there were more questions than solutions for the care and management of digital works, faculty boldly tackled investigations involving real world digital collections and undertook research projects large and small. Besser led MIAP's involvement in Preserving Digital Public Television, a multi-year research project with US public television entities and NYU's emerging Digital 
Library that set out to design systems and infrastructure for a shared repository. ${ }^{3}$ By contrast, in the 2007 Digital Preservation class I engaged the students in analysing risks for small-scale digital video productions, resulting in practical workflows aimed at creators and archivists new to digital video materials (Ranger et al., 2007).

In coursework or through theses, students have created new knowledge about digital processes. Some faculty have incorporated these concepts or the papers themselves into the curriculum. For example, Jonah Volk's thesis raised awareness of the types of files generated by early digital cameras and the risk of data loss if one reorganized the arrangement of the files and directories (Volk, 2010). Athena Holbrook's thesis included customization of the content management system Collective Access and revealed important information about the advantages and disadvantages of the software for use by small organizations and individual creators (Holbrook, 2014).

\section{Modelling meaningful collaborations}

A commitment to collaboration has enabled MIAP to grow in ways that we could not have anticipated. The participation by Besser and MIAP alumna Kara Van Malssen in SOIMA, for example, has brought us in contact with new partners across the globe, as evidenced in this collection of papers. Through the Audiovisual Preservation Exchange, MIAP brings together professionals and students internationally to learn from each other through shared work on collections. The inaugural APEX project, APEX Ghana, culminated in a collaboration with SOIMA graduate Judith Opoku-Boateng to establish an audio preservation lab at the Institute of African Studies at the University of Ghana (see OpokuBoateng's contribution in this volume). Hundreds of priceless audio recordings of Ghanaian music and oral traditions have been saved and made accessible through the Making African Academic Resources Accessible (MAARA) initiative. ${ }^{4}$ Annually in Collection Management class, students examine the collections assessment report created as part of the MAARA planning process, and they learn about how the plans for digitization and a digital repository became a reality.

In APEX Santiago, held in 2016, participants installed a new digitization lab at the community television station Señal 3 La Victoria. ${ }^{5}$ In the process, the team documented how such a lab can be created at a low cost and on a tight timeline. APEX is an example of a programme where MIAP goals for

3 See www.digitalpreservation.gov/partners/pdpt.html and www. thirteen.org/ptvdigitalarchive/.

4 For more on MAARA, see www.apexghana.org.

5 See https://apexsantiago.wordpress.com/. a solid curriculum in digital methods and an interest in international networking and collaboration meet.

\section{Learning from new professionals}

No programme, especially one as small as MIAP, can stay current on every single change and innovation that is occurring in our field. MIAP has been strengthened through an openness to listening and learning from our graduates (and our students) and their allies. It is exciting and inspiring to see new professionals crossing disciplines, melding practices and using new social networks so fluidly. They are immensely creative in their approaches to problem-solving digital matters. For example, in 2013 our alumni organized the first AMIA/DLF Hack Day, bringing archivists (from the Association of Moving Image Archivists) and programmers (from the Digital Library Federation) together to work on issues facing audiovisual digital preservation. ${ }^{6}$ They tackled practical problems - for example, how can we make a software that can move technical metadata about a file extracted from a tool like Media Info into our collection database? A number of our graduates also teach in our programme, and their voice in curriculum planning is crucial. With regard to international networking, former student organizers of APEX projects have helped shape and improve the annual programme, and they generously serve as mentors for those who come after them.

While the above examples focus more on what has catalysed our adaptations to the digital, over the last 13 years there have been many discussions within MIAP about how to be more authentically global in our reach and participation. These discussions have included how to better attract and support international students (affordability continues to be a serious issue); how MIAP might potentially expand and develop educational offerings in other geographic areas; what constitutes ethical and effective international exchange; and how the curriculum can better reflect what we have personally and collectively gained from our international collaborations.

To answer Aparna's original charge, I have concluded that adapting to an increasingly digital and globally networked world is not primarily about technology. Teaching moving image archiving and preservation is not only about being up to date; it is not only about having new knowledge that can be simply passed along by an instructor. There is certainly a place for didactics, but a worthwhile education is more about observation, listening, communication and public engagement; it is about creativity, experimentation, learning

\footnotetext{
6 See www.amiaconference.net/announcing-the-first-amiadlf-hackdayl.
} 
from others and being generous. I have been fortunate to be part of a team at MIAP and within the Department of Cinema Studies that was forward-thinking and inquisitive; strove to be inclusive of all media types, makers and collectors; and valued exchange, whether at the local, national or international level.

\section{Conclusion}

MIAP has adapted its curriculum many times based on a combination of factors. Programme director Howard Besser articulated a broad vision for MIAP and for the future of digital archives; his vision, along with the experience and interests of the team of faculty and staff, set the stage for a foregrounding of digital issues. The programme's original curriculum included digital components, and the inclusion of video and multimedia along with film as important heritage materials helped shape teaching and research on digital issues. Also, MIAP stressed and encouraged principles such as collaboration, practical work in collections and creative research, and it manifested these principles on local and global levels. A range of partners, including MIAP's own alumni, have been essential to how MIAP has evolved and grown.

\section{References}

Holbrook, A.C. 2014. From artist to archivist: portrait of the Joan Logue collection. New York University. (MA thesis)

Melville, A. \& Simmons, S. 1993. Film preservation 1993: a study of the current state of American film preservation. Washington DC, Library of Congress, June 1993. (also available at www.loc. gov/programs/national-film-preservation-board/preservationresearch/film-preservation-study/current-state-of-americanfilm-preservation-study/).
Murphy, W.T. 1997. Television and video preservation 1997: a report on the current state of American television and video preservation. Washington, DC, Library of Congress, October 1997. (also available at www.loc.gov/programs/static/nationalfilm-preservation-board/documents/tvstudy.pdf).

Ranger, R., Resnick, S., Shibuyama, L. \& Sorenson, L. 2007. Best practices report for Deep Dish Television: Shocking and awful: a grassroots response to war and occupation (unpublished). (also available at www.nyu.edu/tisch/preservation/program/ student_work/2007fall_2/f07_1807_groupfinal.pdf).

Volk, J. 2010. A producer's guide to preserving file-based digital video. New York University. (MA thesis)

Mona Jimenez started transferring obsolete videotapes in the late 1980s and has been an advocate and organizer for the preservation of independent media and media art ever since. She is Associate Arts Professor/Associate Director in New York University's Moving Image Archiving and Preservation Program, where she teaches the preservation of video and digital works. She is co-editor with Sherry Miller Hocking and Kathy High of The emergence of video processing tools: television becoming unglued, which documents collaborations between artists and technologists to create custom tools for media art. Since 2009 she has been experimenting with participatory models of media/ film archiving locally and through Community Archiving Workshops organized by the Independent Media Committee of the Association of Moving Image Archivists. She is the founder of Audiovisual Preservation Exchange (APEX), a project to network audiovisual archivists, educators and students internationally through shared work on collections. 